\title{
Socio-ecological Modeling of Risk Factors of Urbanized Territories' Development
}

\author{
T.Y. Anopchenko ${ }^{1}$, K.T. Paytaeva ${ }^{2}$, L.A. Novoseltseva ${ }^{1}$, \\ M.A.Chernyshev ${ }^{1}$ and A.D. Murzin ${ }^{1}$
}

${ }^{1}$ Faculty of Management, Southern Federal University, Rostov-on-Don, Russia. ${ }^{2}$ Faculty of Economics and Finance, Chechen State University, Grozny, Chechen Republic.

DOI: http://dx.doi.org/10.13005/bbra/1936

(Received: 06 September 2015; accepted: 17 October 2015)

The article deals with the problem of forming an effective approach to modeling of integral indicator of socio-ecological risk in elaboration of urbanized territories development scenarios. The main objective is to develop economic-mathematical model of socio-environmental risk assessment and justification of starting parameters for its realization. During the research, the authors studied in detail the existing approaches to the modeling of ecological and economic factors; considered the stages of interaction between man and nature characterizing the manifestation of risks; revealed the peculiarities of the concepts of "risk" and "damage"; defined the evaluation methodology and indicators of environmental sustainability. On the basis of existing approaches to modeling of economic growth with the social index, the criterion of population health and the indicators of the ecological state of the territory, the authors have developed the model of integral risk. In detailed review of the fundamentals of modeling: Forrester's methods of system dynamics (and subsequent works of D. Meadows) and Leontiev's "input-output" (and subsequent papers of D. Ford), is the necessity of employment of the risk index in socio-ecological models is proven, and the methods of the convolution of partial indices and the possibility of consideration of multiplicity of risk factors are substantiated. The main result of research is the scientific basis of usage of multiple choice models for construction of integral indicator of socio-ecological territory risk.

Key words: Modeling, socio-ecological risk, development of urbanized areas, integral indicator, multiple choice models.

Modern urbanized environment of municipal areas in Russia is characterized by serious socio-ecological violations, caused by large-scale pollution of atmospheric air, surface and subsurface soils and water bodies (Bakumenko and Korotkov, 2008).

\footnotetext{
* To whom all correspondence should be addressed. Tel.: + 7(863) 250-59-63;

E-mail: admurzin@yandex.ru
}

Since the middle of 1990-ies many experts have noted positive ecological dynamics of urban area, which is mostly explained by the decline in industrial production typical for the period (Mashintsov, 2007). But with the economic growth and the development of industrial relations in 2000ies the the environmental situation in the cities shows a negative trend that is accelerating due to the high moral and physical deterioration of production facilities (Tsyganov, 2007). In the current situation, for the polluter it is economically more profitable to pay the fines than to prevent 
environmental violations and upgrade fixed assets (Pashkova, 2008). Exploitation of the principle of a quick profit with extensive use of natural resources contributes to a sharp increase of the load on the cities' natural and anthropogenic environment (Dvoretsky, 2006).

The deterioration of the ecological parameters of the environment and the intensification of human impact on nature involve violations of natural-anthropogenic stability and increase the negative socio-economic consequences probability, expressed in increasing the population morbidity, the growth of economic losses and fiscal costs, on the scale from individual enterprise to urban agglomeration (Anopchenko, 2008).

\section{Theoretical Framework}

In connection with these circumstances the modeling of socio-ecological risks management processes in the process of urbanized areas development planning is relevant and affects the interests of the entire social community, defining long-term priorities on the safety of the environment. Problems of ecological and economic interconnections' modeling and processes of the impact of economic factors on the environment in global aspect were touched in the studies of Leontiev V., Meadows D., Mesarovich M., etc. The meso-level of socio- ecological modelling and the problem of socio-economic assessment of damage from ecological pollution were considered by Girusov E., Gurman V., Danilov-Danilyan V., Ryumina E., etc. The individual tasks of economicmathematical modeling of ecological-economic risks management were solved by Anopchenko T., Patronym I., Tikhomirov N., etc

At the same time many researchers use data from the official publications on ecological pollution as information. That data, as a rule, does not account for unauthorized discharges and emissions, which leads to a weak objective nature of the results and reduces the practical significance of drawn conclusions. Sets of criteria used to assess the ecological state of the environment, often reflect only the degree of anthropogenic influence on human activity, and do not reflect the risks of social damages.

Despite the exposure of urbanized areas to a variety of socio-environmental risks, at the present time virtually no scientific work is devoted to the complex study of these risks' nature, level of their influence on socio-economic indicators and uniformity of development of the city. Also some of the practical tasks in this area, for example, associated with the ranking and comparative analysis of objects according to the degree of socio-economic risks, are not fully explored.

Nowadays there are many approaches to the definition of concept of risk; every sphere of public life is dominated by interpretations.

The synonym for the concept of "risk" is the word "danger". Khokhlov (2001) defines risk as "a random event causing damage to the object", in the work of Gracheva and Sekerin (2009) risk is understood as "the event (possible danger) which may happen or may not happen". In other words, in the Russian practice the interpretation of the concept of risk also includes "danger" that characterizes the "objectively existing possibility of negative impact on the studied object that can bring any harm, damage" (Tikhomirov at al., 2003). Consequently, the concepts of risk and danger are comparable synonyms, and the term of characterizes losses arising as a result of the state change, the modes of object operation due to adverse events.

Risk can be defined by both qualitative and quantitative parameters. An example of the former is the fact of the accomplishing or the absence of a risk event, the latter can be represented by the magnitude of the loss (damage) of the object when realizing the unfavorable factors, the likelihood of adverse events, an indicator of medium risk (medium expected loss) (Tikhomirov at al., 2003), coefficients and/or hazard indices (Dubrov at al., 2001; Sholomitsky, 2005), etc.

In some cases concepts of "risk" and "risk measure" can be identified, characterizing the probability of adverse events (Dubrov at al., 2001; Chetyrkin, 2000). For example, the Russian Federal law “On technical regulation” (2002) defines risk as "the probability of harm to the life or health of citizens, property of physical or legal persons, state or municipal property, environment, life or health of animals and plants based on the severity of that harm".

The change in the scope and complications of interaction between man and nature and extent of the impact of human activity on the environment give rise to ecological and 
socio- ecological risks. Historically, this process can be divided into three stages.

The initial stage is characterized by unilateral effects, in which only the man was vulnerable to these risks (fig. 1). At this stage, there was a gradual awareness of possible hazards, man has sought to meet the basic needs what prompted him to develop agriculture, industry, medicine, etc. These circumstances led to the first ecological crisis (consumers and producers) (Kolesnikov, 2005). However, human impact on nature was relatively low.

At the second stage the reduction of the impact of nature on humans followed, due to the development of industries, agriculture and medicine, which began to serve as a protective barrier (fig. 2). However, by developing these areas, the society has begun to exert increasing pressure on the natural environment, which ultimately led to a second ecological crisis (decomposers and thermodynamics) (Kolesnikov, 2005). This stage allowed us to recognize the exposure of nature itself to various risks, including those caused by human activities. This is the time of the occurrence of the phenomenon of ecological risk. However, the man is still subject to natural risks, he learns to manage and compensate for their negative consequences. In general, at this stage, a significant increase of anthropogenic load on the environment has not yet exceeded the level of potential capacity (assimilative capacity) of the biosphere, which was reflected in insignificant level of additional risks for the society and the economic sphere from the natural environment.

According to research of Dennis and Daniella Meadows (2004), the modern stage is characterized by excess of societal needs over capabilities of natural environment, decrease of qualitative parameters of which becomes more pronounced (Meadows at al., 2004), what in its turn conditions the restrictions for development of economy branches and society as a whole. In other words, in a system of man-nature interaction there appear factors contributing to reduction of anthropogenic load on environment. At present (the) development of society as a complex socioeconomical system is accompanied by rise of new issues in process of solution of current problems, increase of contradictions between development of separate subsystems and well-being of the whole system, low effectiveness of methods of influence on the system as a whole (Forrester, 1971). As a result of these processes society is forced to reconcile with losses connected to ecological dysfunctions, which influence the man not only indirectly (as a result of accelerated wear of primary funds), but directly as well - as a result of increase in sickness and death rates of polluted area inhabitants (Fig. 3).

In present conditions any anthropogenic activity must be evaluated from environmental safety position, i.e. it has to be accompanied by ecological risk analysis. According to Reimers' opinion (1990), ecological risk should be determined by probability of ecologically adverse consequences for any anthropogenic changes of ecological objects and factors, in other words, ecological risk is only considered in light of technogenic events (Dediu, 1989).

In Russian legal system ecological risk is determined by probability of event which has adverse consequences for environment and is summoned by negative influence of managing and other activities, ecological and technogenic emergencies (Russian Federation. Laws, 2006). In other words, law system considers that risk not only as technogenic event, but also as an ecological and mixed event. That interpretation coincides with international practice of applying the term "ecological risk", which characterizes the probability of adverse influence on biosystems, flora and fauna.

At the same time, some scientists are prone to considering ecological risk as civil responsibility for damage inflicted upon environment as well as damage to life and health of people (Khokhlov, 2001). But legal system and normative-methodical documents use concepts of "risk for health", "risk of violation of health and disease control ambience", "oncogenic risk" and others are used to characterize the adverse influence on people's health (Onishchenko at al., 2002). While in the international organizations' practice of the description of these risks, it is customary to use the term "environmental risk", i.e. the risk is conditioned to the impact on the environment. In our opinion, this type of risk is most appropriate to identify how the risk of damage to the environment and not to include in this concept the damage to humans. 
Consequently, socio- ecological risks can be adequately defined as the risks of socioeconomic losses and damages of various objects due to deterioration in the quality of ecological parameters or ecological violations (Tikhomirov at al., 2003). The economic component of this term characterizes the membership of risk subjects to the economic subsystem, and incurred losses and cost expression. Ecological component determines the nature of risk and indicates the reason.

The object of socio- ecological risks can be expected to deliver individual and the population as a whole, the organization (enterprise), territorialenvironmental complex, territorial production system, region, state, the world community (Tikhomirov at al., 2003). In this case, the deterioration of the quality of ecological parameters can have both evolutionary and catastrophic nature. However, negative changes in the environment do not always lead to economic damage. So even ecologically caused diseases, and hence economic damage, are not all exposed to negative factors of the individuals, but the risk of this event, forming a threat of loss of health, had a place for everyone.

As a result of implementation of socioecological risks socio-economic damage caused by environmental disturbances (socio-ecological and economic damage) is manifested, which is unambiguous evidence of existing threats, although it may be while not identified and adequately assessed.

Environmental violations can be divided into several groups: caused by human activities (emissions and discharges of pollutants, man-made accidents and resulting from natural processes (natural disasters), as well as mixed character (the catastrophic effects of anthropogenic activities).

In our opinion, the next logical sequence of formation of the economic damages from ecological factors is appropriate: 1) pollution by acting on components of the environment, in General, changes its qualitative state; 2 ) a modified environment, influencing the recipient, causes economic damage (Ryumina, 2004). As recipients of the changed environment may act population, housing and household facilities, objects of agriculture, animal and plant resources, industrial facilities, recreational resources and health-resort zone. The negative effects that determine the natural damage of recipients can be manifested by loss of life, deterioration of their health status, deterioration of environmental quality, agricultural and recreational resources, loss of fixed assets, objects of housing and communal economy, the decline in production (Ryumina, 2004).

According to Onishchenko (2002), there are around 20 chronic diseases currently identified, manifested as a result of negative ecological factors: asbestosis, siderosis, Jackofsky asthma, Minamata disease, Itai-Itai, Uchaud, etc. in this case, quantification of economic damages can be made for the valuation of losses from the reduction or complete loss of working capacity as a result of the disease. Thus, in the study of the causes of many health problems it is difficult to determine the relationships between the specific diseases and adverse ecological effects. However, quantitative estimates may be subject to additional likelihood of developing certain diseases for certain groups of the population, the risk of disease given individual can be determined only with low accuracy.

In this regard, we agree with the identity of the concepts of socio- ecological damage and risk. This is confirmed by the research of Ryumina (2000), in which there is a speech about the "assessment of economic damage through the risk category". You should split a posteriori, assuming as accurate as possible a record of all losses, and a priori, describing the possible (potential) losses, estimates of economic damage. The concept of risk, in our view, is more in line with a priori assessment of the damage. Determining the magnitude of the damage as a measure of risk is reduced to the evaluation of socio- ecological damages. However, the measure of socioecological risk may address only the likelihood of any damage.

In the aspect of risk, the sequence of formation of socio-environmental damage is modified: 1) pollution by acting on components of the environment, in General, change its qualitative state; 2) recipients, functioning in a modified environment, are subjected to socio-ecological risks.

The mapping of objects on the level of risk in view of the impossibility of determining the probability and magnitude of losses are possible on the basis of the ranking of the corresponding 
damage (Chetyrkin, 2000). In this regard, we should pay attention to personal-subjective perception of risk. Thus, the subject's risk (investor, entrepreneur, households) as a rule, are not interested in the absolute level of risk of any object and its compliance with normal values, and its relative value in comparison with similar objects. Furthermore, the object can be simultaneously exposed to multiple risk factors, to evaluate which you want to use a single index and rank by the value of the integral risk or risk dynamics of the object. This approach should not be regarded as a necessary measure in conditions of incomplete information, and as a complementary tool in the assessment and management of risk.

The content of the term and the definition of the relevant measure of risk is determined by the specific area of application, amount of information available, the quality and form of its presentation, the areas of use of the results, it is therefore necessary to consider in detail the existing approaches and methods for assessing socio- ecological risk.

The content of the term and the definition of the relevant measure of risk is determined by the specific area of application, amount of information available, the quality and form of its presentation, the areas of use of the results, it is therefore necessary to consider in detail the existing approaches and methods for assessing socio- ecological risk.

\section{Methodology}

An important aspect of the development of socio-ecological-economic models is the identification of groups and systems of indicators characterizing the condition and quality parameters of the natural and anthropogenic. As a rule, attention is directed to any one of the possible indicators - the number of available natural resources, the sheer volume of the discharge of pollutants, their concentration, etc. However, in our opinion, to assess the socio-environmental risk factors of territorial systems need to use more extensive information, i.e. there may be a need to integrate quality indicators, status, security, and environmental sustainability into a single criterion that characterizes a certain territory.

In studies of Bakumenko and Korotkov (2008) an overview of the global practice of formation of the integral indicators of the environment is provided, the most famous of which are "ecological footprint", "living planet" and "environmental sustainability”.

The ecological trace represents the resource demand of the society, the measured equivalent productive land area or water area required to meet this need, and disposal of generated waste (Wackernagel and Rees, 1998). The methodology of the ecological footprint is based on several prerequisites:

1) man is an integral component of ecosystems which provides everything he needs;

2) the main purpose of the human impact on the ecosystem is the extraction and consumption of energy and materials;

3) the volume of produced energy and material resources can be measured by the area of providing or carrying their territory.

The ecological trace of a particular region may depend on the size of its population, the level and quality of life, territorial productivity, efficient use of natural resources. To map the indicator ecological trace of various regions can be used the criterion of "global hectares", characterized by the average productivity of the territory. Statistical observation of the indicator ecological trace revealed a direct correlation of its values with the income level of the region, i.e. the more successful urban areas, the greater their impact on the environment (Dewulf and Langenhove, 2006).

According to the structure of the indicator ecological footprint is a static, despite this, it is quite suitable for use in models designed to study the impact of lifestyle changes and the level of technology on the environment, the results of which are developing policies for sustainable development of territories. This indicator allows you to rank site and highlight the "debtors" and "creditors", and to calculate the environmental index of the person but does not include socioeconomic (Dewulf and Langenhove, 2006). Therefore this indicator cannot be regarded as summarizing the characteristics of the interaction of society and the environment and requires an additional consideration of social indicators. In addition, the indicator ecological footprint does not consider the availability of fresh water, which is important for human resource ecosystems, which cannot be reflected in global hectares. 
Measuring the availability of water resources is considered to produce an indicator of water stress, characterizing the amount of water withdrawn from surface and groundwater sources, in proportion to the standard permissible level.

"Living planet" index is defined by biodiversity areas and includes taking into account changes in the population of traditional species. Over the last 30 years the ratio decreased by $30 \%$, which caused a rapid rate of destruction of ecosystems.

The definition of the index of environmental sustainability (Environmental Sustainability Index, ESI), developed at Yale University (New Haven, Connecticut, USA), a complex of 76 indicators, grouped into 5 global component is used (tab. 1) (Esty et al., 2005).

Convolution of these indicators into a single index must be preceded by rationing, check for missing data using different methods (simulation modeling, regression analysis, etc.), and vinsoring. Directly convolution is performed by summing all of the indicators with equal weights, due to the need for simplicity and transparency of the composite indicator that can expand its scope.

The performed calculations of the environmental sustainability index expert given weights and the calculation of weights based on the analysis of indicators by principal component method do not detect significant differences in the results obtained (Esty et al., 2005). The result of applying the latter method is getting 6 principal components to explain up to $75 \%$ of the variance of the original indicators that are strongly correlated with the received components. This fact demonstrates the importance of accounting for all included in the calculations of indicators and multidimensionality of criteria of environmental sustainability, which cannot be described by a limited number of indicators (Esty et al., 2005).

You should consider the results of the comparison of indices of environmental sustainability and ecological footprint, which is included in the calculation of the composite index (tab. 1, p. 2). In this context, it is natural to found an inverse correlation index, ecological footprint and pressure of waste and consumption, variation which explains $15 \%$ of variance of the environmental sustainability index. However, the overall correlation of the indices of a positive nature, i.e. areas with a high level of consumption of natural resources, characterized by positive dynamics of the index of environmental sustainability.

In our view, the incompatibility of high resource consumption and environmental sustainability in the long term is certain, however, the weakness of the ecological footprint does not guarantee the environmental sustainability of the territory, as may be caused only by the low economic activity and low reserves of natural resources. At the same time, territories and regions with a strong ecological footprint and a high level of economic activity have greater potential for protection from the negative effects of pollution and investment in mitigation. Therefore, to increase the objectivity of the comparison of the considered indices should at least be excluded from the calculation of the factor income.

Nevertheless, the environmental sustainability index, being a linear function of the baseline, is not valid under conditions of partial non-compensability, when critical values exist for the constituent indicators that define the threshold of their compensation at the expense of other indices of the integral indicator (Aivazyan, 2002; World Bank Group, 2012). This fact is the main argument for an imperfection of indicator of the environmental sustainability index, as the desire to increase the value of this index can only lead to the transition from one unstable state to another, declared as the improvement of the situation.

Thus, as the main conclusion of the analysis, we confirm the necessity of recognition of the utility of the aggregate level of such indices, but given the constraints of their application, conditioned by lack of ability of taking into account mutual influence and communication between the included indicators and weak identification of the problem area. Disaggregated indicators in this regard, in our opinion, have great advantages in the reflection of the territorial problems, allowing them to diagnose and to take countermeasures. Integration of these indicators is appropriate to the level of the key developmental areas: social (health, education, housing, security levels, etc.), ecological (air, water, land, biodiversity states, etc.), economic (income, industrial development, interregional cooperation levels, etc.), etc.

The most known systems of ecological 
indicators of the environment are the criteria of sustainable development proposed by the UN, the ecological indicators developed by the Organization for economic cooperation and development, indicators of improved ecological management, used by the World Bank, as well as a set of criteria for sustainable development in the UK.

The indicators of most existing systems are selected for their policy relevance, analytical soundness and possibility of accurate measurements. The basis of this choice is the pressure - state - response model. The first component of this model characterizes the "pressure" of human activity on the environment, "state" of which is characterized by a change in the number of high-quality natural resources. The changes create a certain "reaction" of the society in the form of ecological and general economic events or sectorial policies, and changing public attitudes and behavior.

"Pressure" is the use of natural resources and emissions / discharges of pollutants, which are closely linked to production and consumption in the region. "State" is characterized by the level of ecological quality (concentration of pollutants, the level of critical loads, the condition of flora and fauna, etc.), as well as qualitative-quantitative parameters available natural resources. "Reaction" reflects the response of society to ecological problems and is to mitigate, adapt to or prevent negative impacts on the environment (financing environment-oriented events at the expense of taxes, charges and subsidies, the reduction of polluted area, recycling of wastes, etc.).

The model allows to identify the causal link between socio- ecological living conditions and economic activities of society, contributes to effective decision-making and transparency of implementation of policy addressing the emerging problems (Forrester, 1971; Assessment of environmental management systems, 2003). This model has been widely used in many systems of indicators and, in particular, served as the basis for developing European indicators of the impact of Eurostat.

In our country the problem of scientific substantiation of systems of ecological indicators and integrated sustainable development criteria is also very important. Thus, studies of Eklasheva
(2005) propose a set of indicators of socio-natural development, integrated indicator of which presents a synthetic index (SI), characterized by the sum of specific industries of physical, human and ecological capital (IPC, IHC and IEC, respectively) (Vagapova, 2007). Physical and human capitals are produced by society, ecological - by biota, and its value is determined in proportion to the specific productivity of the environment.

In the works of Vagapova (2007) economic growth model is proposed, basing on the environmental index, which takes into account socio- ecological factors of development and which characterizes changes in the environment due to the produced in year $t$ emissions / discharges of pollutants $x_{1}(t)$, the area disturbed as a result of managing land $x_{2}(t)$ and the volume of contaminated water resources $x_{3}(t)$ in comparison with the base year $t_{0}$ :

$$
\theta(t)=\sum_{i=1}^{3} \alpha_{i} \frac{x_{i}\left(t_{0}\right)}{x_{i}(t)}
$$

where $\alpha_{i}$ is the weight chosen by the researcher, $\alpha_{i}$ $\geq 0, \sum_{i=1}^{3} \alpha_{i}=1$.

As can be seen from the formula (1), the environmental index is associated with a environmental pollution decrease.

Scheme of social index construction, $r(t)$ is similar and involves the assessment of relative changes of social indicators compared to the base year $t_{0}$, this takes into account indicators of the health of the population $z_{1}(t)$, social security $z_{2}(t)$ and welfare $z_{3}(t)$ :

$$
r(t)=\sum_{i=1}^{3} \gamma_{i} z_{i}(t)
$$

where $\gamma$ i is the weight, i.e. $\gamma_{i} \geq 0, \sum_{i=1}^{3} \gamma_{i}=1$.

The level of health of the population $z_{1}(t)$ is determined on the basis of statistics data, on indicators of life expectancy $z_{11}(t)$, morbidity per thousand $z_{12}(t)$ and the number of disabled people in society $z_{13}(t)$ :

$$
z_{1}(t)=\beta_{11} \frac{z_{11}(t)}{z_{11}\left(t_{0}\right)}+\beta_{12} \frac{z_{12}\left(t_{0}\right)}{z_{12}(t)}+\beta_{13} \frac{z_{13}\left(t_{0}\right)}{z_{13}(t)}
$$


where $\beta_{i j}$ is the weight, $\beta_{i j}>0, \sum_{i=1}^{3} \beta_{i j}=1$.

For the construction of an indicator of social safety $z_{2}(t)$ the level of unemployment, the stratification of society, the proportion of the population with incomes below a living wage etc. are taken into account. Welfare indicator $z_{3}(t)$ is characterized by the supply of housing, per capita income etc.

The weights ãi and âij are determined by the specific purpose of the research. So, to study the impact of population health on economic growth, the priority is set for the first factor $\left(\gamma_{1}=1\right.$, $\gamma_{2}=0, \gamma_{3}=0$ ), to specify the terms of the equal importance of all three factors, their weights are set equal to the proportionate $\left(\gamma_{1}=\gamma_{2}=\gamma_{3}=\mathrm{S} 1 / 3\right)$.

As can be seen from the formula (2), the growth of social index is provided in case of improvements in the social sphere of a certain area. Therefore, the integral indicator of sustainable development according to this method is a linear function of individual indicators according to their importance (weight). However, the weighting of each indicator is the main drawback of this method, as this approach is characterized by a high degree of subjectivity.

Sholomicky (2005) proposes an integrated comparative assessment of the ecological state of the territories on the basis of a set of indicators that includes multiple blocks: 1) the anthropogenic impact of production and economic activity; 2) the efficiency of environment-oriented and resourcesaving measures; 3) the level of usage of energy resources. Integral indicator of sustainable development is proposed to calculate with the coherent summation of the ratings of all blocks with their pre-regulation and the receipt of private comparative evaluations as a result of simple transformations. However, testing of this technique found a fairly high degree of inadequacy of the assessments for individual areas (up to 38\%).

However, it should be noted that the conceptual basis of the systematization of the elements of the integral indicator of the state of ecological subsystem suitable for domestic conditions were laid down by Ayvazyan (2002) in the works devoted to the problem of life quality evaluation. He offers to determine an integrated characteristic of the conditions of life on the basis of the "ecological niche quality" and "climatic conditions level” indicator (Aivazyan, 2002). However, the application of methods of indicators' convolution and ways of integrating ecological indicators of inter-territorial comparisons were not considered.

Ecological niche's quality index should include five individual criteria: the quality of air, water and soil resources, biodiversity of the territory and state of natural ecosystems. The level of natural-climatic conditions should be determined on the basis of three criteria, which are not considered in detail because of the lack of standards and ecological monitoring. As a result of testing the methods the built integrated indicator of quality of life explains up to $70 \%$ of variance of a posteriori criteria.

The works of Ryumina (2011) are a logical follow-up research of this problem, entirely devoted to the problem of building an integrated indicator of the ecological state of the region. It is proposed to include six elements into this integral index: 1) air, 2) water, 3) land, and 4) forest resources of the territory, as well as 5) state of the animal world, and 6) biodiversity. This does not include the storage and disposal of toxic waste. In the process of testing the method the ecological stability of the region was determined by the indicators of "quality of technosphere" and "ecosystem quality”, calculations of which explain up to $79 \%$ variation of the initial indicators, and the results of the analysis of indicators dynamics showed growth trends of composite integral indicator, which means the possibility of levelling the technosphere quality reduction at expense of the rapid growth of ecosystem quality.

\section{RESULTS}

Generally socio-ecological modeling is understood as a formal description of the relationships and interaction of social and ecological processes and socio-ecologicaleconomic models are descriptive mechanisms of global, regional or territorial level of interaction between the social sphere and the environment in the process of economic activity (Lopatnikov, 2003).

For many decades it was believed that economic development and economic activity is 
enough to ensure normal conditions of human life, but recently the problem of reproduction of favorable natural conditions is becoming more and more evident, i.e., economic system is included in the global system of the planet noosphere. The smallest valuable unit of the noosphere is the socioecological system, and in some cases - socialecological-economic one. Some scientists (Grinin at al., 2003; Murzin, 2012) have addressed the problem of elaboration of guidelines for modeling the functioning of such systems.

The main principle of economicmathematical modeling of risks of social-ecological systems, in our opinion, is the uncertainty principle, according to which, firstly, there are factors, a small deviation of which does not entail significant changes to the stable state of the system, and secondly, individual property or quality of any system process is valid only in a particular time and in the current environment. Hence appears the necessity of taking into account the random nature of changes in factors of socio-ecological processes at the level of individual territory.

The initial stage of formulation of the tasks of modeling the interaction of social, ecological and economic processes can be recognized as the period of tangible interactive impacts of human activities and the environment (1970s). At this point, the first research and models of environmental pollution and its effects on humans start to appear. Cause of the origin of this scientific field was the buildup of negative changes in the environment, conditioned by technological revolution, weak awareness of ecological issues and the need to develop ways to neutralize them (Peccei, 2013).

It is possible to allocate two basic approaches to socio-ecological modeling (Fig. 4) (Gurman and Ryumina, 2003).

The first approach is based on the ideas

Table 1. The system of environmental sustainability index indicators

Name of the component $\quad$ List of criteria ESI

1. The environment (17)

2. Reducing the impact on environmental resources (21)

3 Reducing human vulnerability (11)

4. Socio-institutional response to environmental challenges (20)

5. Global monitoring of the ecological state of the territories (7)
1.1. qualitative parameters of air resources (4)

1.2. qualitative parameters of water resources (4)

1.3. quantitative parameters of water resources (2)

1.4. qualitative parameters of land resources (2)

1.5. biodiversity (5)

2.1. reduction of pollution of air resources (5)

2.2. reducing the pressure on the ecosystem of the territory (3)

2.3. the pressure reduction of waste and consumption (4)

2.4. reducing the pressure on water resources (4)

2.5. streamlining the management of natural resources (5)

3.1. the environmental improvement (3)

3.2. satisfaction of primary human needs (2)

3.3. satisfaction of secondary needs of man (2)

3.4. reduction of morbidity due to pollution of nature (2)

3.5. reducing mortality due to natural disasters (2)

4.1. management of environmental quality (6)

4.2. improving the eco-efficiency of the territories (2)

4.3. environmental orientation of education (5)

4.4. the development of environmentally friendly industrial technologies (5)

4.5. the involvement of private capital in the environmental sector (2)

5.1. participation in international environmental projects (3)

5.2. control of emission of greenhouse gases (2)

5.3. reducing pressure on transboundary territory (2)

Note. In parentheses there is the number used to identify each criterion indicators. 
of Forrester (1971) stated in "World1", "World2" and "World3", on the last of which worked a group of authors under the direction of D. Meadows (Meadows at al., 2004). These studies are based on general systems theory and principles of system dynamics and include serious mathematical apparatus of differential equations and computer models. The main conclusion of the authors of the research, built on the world's ecological statistics data, is the possible near global catastrophe if the current rates of population growth, consumption of natural resources and environmental pollution are upheld (Krass and Chuprunov, 2007).

The main feature and a disadvantage of this model is the consideration of global socioecological system as a whole, without division into separate regions and territories, which may have specific development factors. The authors determine the main purpose of this model as to attract public attention to the growing ecological 1 problems, attempt to influence the way of thinking and the political will of society. Management instrumentation for individual territorial systemsis not included in this model, however, it served as the basis of many more complex models of the next level, allowing assessment of the impact of management decisions on the simulated socioecological and economic processes.
One of such developments is a simulation model of K. Saied (1988), who considers the sustainability of socio-ecological-economic system, including subsystems of natural resources, population and administration, as the main factor of development of territories and regions. In studies of Eklasheva (2005), devoted to the modelling of economic dynamics of the city in the aspect of ecological factors, the last are regarded as pollution and usage of natural resources, and the system of the city is represented by three subsystems: economic, ecological and social. However, existing models typically examine the processes of resource management, referring to the social sphere only in the aspect of population and its resource provision, without considering the quality of life.

Another model, developed to describe the nature of the influence of human activities on the natural environment, is the model "Gaia", developed under the leadership of academician $\mathrm{N}$. Moiseyev. This model allows prediction of the long-term consequences of nuclear war in the aspect of global climate change and the state of the biosphere. As a result of these studies the possible consequences of the nuclear arms race were seriously rethought.

By the early 70-ies V. Leontiev expanded his theory of "input-output" to consider the

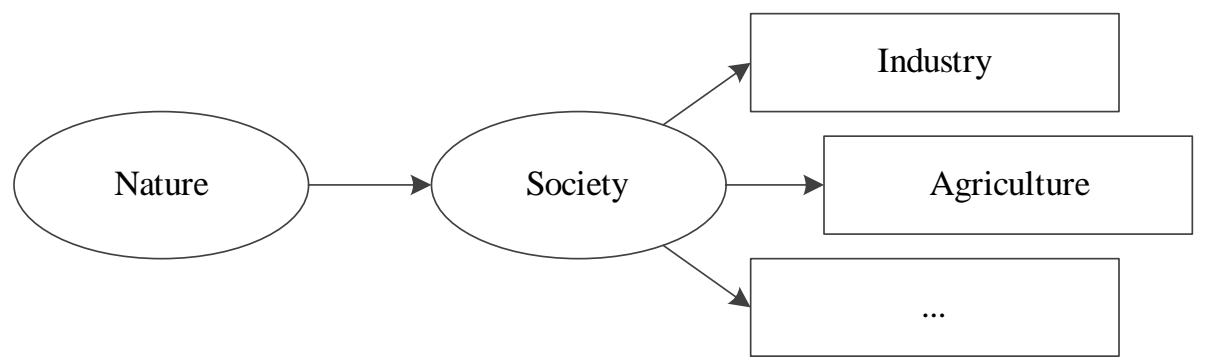

Fig. 1. The first stage of interaction between man and nature

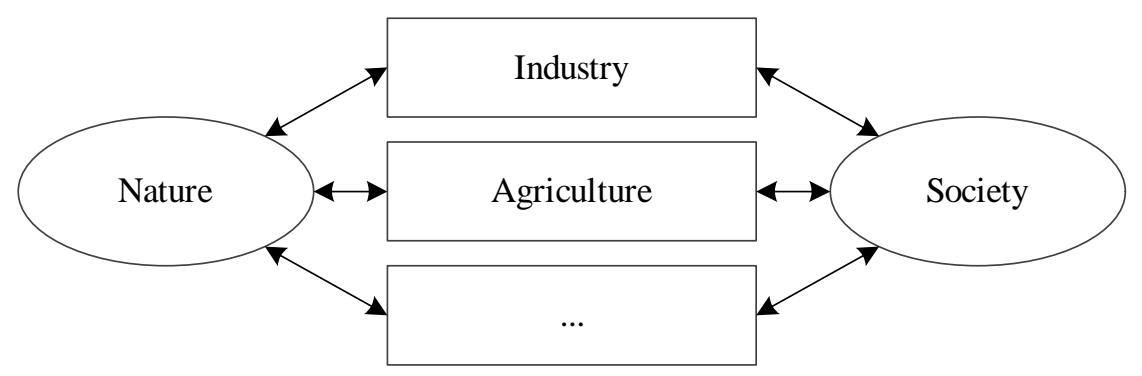

Fig. 2. The second stage of interaction between man and nature 
ecological factor of the inter-industry balance (Leontiev, 1997). The expanded theory proposes obtaining not only useful but also by-products, which are expressed by environmental pollution, as the results of any economic activity. In this regard, the opportunity of costs of certain resources for processing the by-products of economic activity that can be implemented through the creation of specialized production facilities should be taken into account in the model of interindustry balance. This approach allows consideration of factors of production of undesirable by-products that are often ignored, but are always involved in the formation of physical interactions that determine the functional state of the socio-economic system.

Technical interconnections between the levels of useful and unwanted products release can be described in terms of the structural coefficients, characterizing the mutual influence of conventional sectors of production and consumption. The conventional technological matrix and a product matrix that characterizes each sector's direct costs of the destruction of units of each type of pollution, and the matrix of coefficients of the pollutants release per unit of useful products industry and per unit of neutralized pollutant of another form, is constructed for this purpose. That allows taking into account the secondary effect of pollution

The Ford-Leontiev model characterizes the economic losses associated with neutralizing pollutants, and costs that mitigate the financial resources of the various sectors, and also allows determination of the degree of influence of possible price changes on the production conditions of each conservation strategy. However, the abilities of taking into consideration the various ecological factors in the inter-industry balance are quite limited and only partially solve the problems of ecological security (Kashenkova, 2009).

Further there was developed a global model of ecological -economic factors of global development, taking into account food production, agriculture, trade and natural resource extraction, production of pollution. Conceptual provisions of this model served as a basis for the development of many models of ecological-economic balance of different levels. For example, researchers N. Tikhomirov and I. Potravny proposed a model of the region based on the equation of dynamics of inter-industry balance and natural resources (Tikhomirov at al., 2003). This model allows analysis of scenarios' of the region development

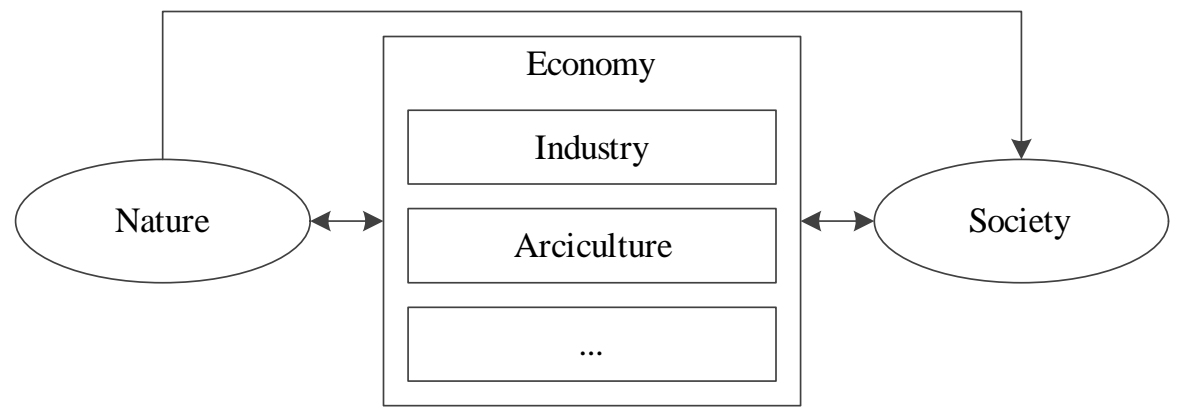

Fig. 3. The third stage of interaction between man and nature

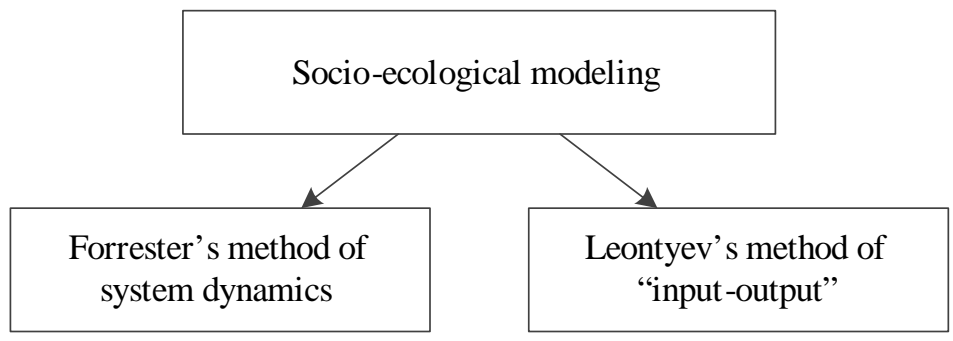

Fig. 4. The main approaches to social-ecological modelling 
on several environmental-economic variables, including, for example, the volume of production of all aggregate industries in the region, or the degree of concentration of pollutants in natural environments, etc.

However, all such models remain focused on the analysis of technological interactions and relationships (Abrahamian at al., 2002), society, quality of life and factors of socio-environmental risk are not taken into account in them, their artificial introduction significantly complicates and disrupts such models, violates their basic concept and structure.

The virtue of models of this type is the possibility of their usage as of elements of more complex models that can operate several variables simultaneously (e.g., natural resources, material production, the volume of pollutants) and provide the possibility of control. So, for the most developed and well known in Russia simulation models in the study of socio-ecological and ecological-economic interactions at the regional level is the model Region, including the units of the inter-industry balance, economic growth and pollutants (Gurman and Ryumina, 2003). This model allows to overcome the problem of erroneous multiple account of homogenous losses, which can be summarized by the entire chain of intermediate products, due to the inclusion of the block of interbranch balance. Here, the region is considered as an open system, which is divided into three interrelated subsystems: social, environmental and economic, and the process of economic damage formation are considered at the level of dependence of the environment on the level of economic activity and dependence of economic results on the quality of the environment. The interaction of social and ecological subsystems and the degree of exposure to sectors of the economy are described here using the corresponding matrices.

In modern terms, some scholars note the need to include in the simulation model the socioecological conditions of development and the block of innovation (Gurman and Ryumina, 2003), account of which is explained by the increasing importance of intangible assets and upgrades of economic development goals. In addition, there are studies on dependence of the environmental situation on the growth of production in the region, the city's economic development on environmental quality, state of the social sphere of urbanized areas on the level of economic development, etc.

So, Brocki W.A. (2013) and some of his followers have developed a model of the interaction of the economy and the natural environment, which considers environmental damage as an additional factor of production and characterizes the dependence of the equilibrium conditions of the capital factor of production on environmental pollution. Korotkov P., in order to improve the basic model of economic growth, offers to complement it with environmental and social units of the kind of Cauchy problems and optimal equation (Bakumenko and Korotkov, 2008), which allows him to conclude that the factors of social wellbeing and environmental quality in conditions of reduction of the population significantly affect the ability of balanced economic growth.

Given by Burkov N. and Novikov D., the overview of domestic practice of modeling socioecological and ecological-economic processes in socio-economic systems (Burkov at al., 2009) allows to select the models of ecological-economic system, monitoring and simulation models, dynamic and optimizational environmental models, models of the interaction of the social sphere and the environment, models of biological systems and its elements, etc.

An econometric model of socioecological factors that characterize the influence of the environment on human health (Mashintsov, 2007), the state of fixed assets (Dvoretsky, 2006), etc., owns a special place in the practice of modeling. These factors were taken into account in the generalized system dynamics models when comparing statistical information on the relationships between the levels of systems. However, their analysis, held with double regression methods, was limited to only a couple of levels, and has also been hampered due to the covert nature of the identified interrelations within the system itself.

The development of econometric apparatus helped to expand the scope of solvable social and environmental problems. For example, studies of Tsyganovs' M. (2007) allowed the development of a complex model of socialecological security of the region, based on the regression equations in which the dependent variables are: the volume of emissions of pollutants 
into the atmosphere, the ratio of discharged polluted water and water intake, as well as volumes of toxic waste; the independent variables are the indicators of the manufacturing sector of the economy, development, construction, environment protection, determined by the method of principal component, and time factor. Positive dynamics of the estimated coefficients in time, indicating the growth trends of all studied parameters of regression equations, are confirmed by the construction of prognosis of dependent model variables using autoregressive and integrated moving average methods. Also, the author of this model uses equations with distributed lags characterizing mortality, life expectancy and morbidity, due to changes in load on the environment in per capita terms.

Dependence of the characteristics of the environment on the parameters of economic activity and health and demographic indicators was identified as a result of the model's testing. Thus, the proposed model defines a scheme of generating socio-economic damage caused by ecological violations of environment similar to the considered "Region" model. In other words, the dependence of the level of anthropogenic pollution on the planned economic growth of major activity types in the short term, which in turn will reduce the level of socio-environmental safety due to the gradual deterioration in morbidity and mortality according to the equations with distributed lags, is predetermined. A detailed analysis of this model also showed a purely formal nature of combining these equations into a single system, since each equation is estimated individually by the author, not taking into account the mutual influence of social, environmental and economic subsystems, and not solving the problem of endogenous regressors.

However, it is possible to highlight some works free of previously identified deficiencies. That is caused by the use of systems of simultaneous equations in the simulation. So, Pashkova A. (2008) proposed a model of "natural damage - socio-ecological and socio-economic factors" in order to ensure the comprehensiveness of the assessments of the socio-economic damage from environmental violations:

$$
\left\{\begin{array}{l}
M=\alpha_{0}+\alpha_{1} A_{2}+\alpha_{2} D+\alpha_{3} P+u_{1}, \\
P=\beta_{0}+\beta_{1} A_{1}+\beta_{2} G+\beta_{3} Y+u_{2}, \\
Y=\varphi_{0}+\varphi_{1} M+u_{3},
\end{array}\right.
$$

where $M$ is the morbidity of the population on a given territory; $A 1$ and $A 2$, respectively, the total emissions of pollutants per capita from stationary and mobile sources; $G$ is the total volume of discharges of pollutants in the hydrosphere per capita; $P$ is the number of polluters per capita; $D$ provision of population health services; $\mathrm{Y}$ is the level of poverty; $u 1, u 2$, u3 - random elements of the regression equations.

It is assumed that $\alpha_{1}>0, \alpha_{2}<0, \alpha_{3}>0, \beta_{1}$ $>0, \beta_{2}>0, \beta_{3}<0, \varphi_{1}>0$.

In the process of this model's testing, the author investigated the state of several regions of Russian Federation, the results of this investigation confirmed a significant negative impact on the value of the damage factors of air pollution and overall improvement of a general environmental hazard level, and the favorable impact of factors of population satisfaction with health services. However, the author comes to the conclusion that the strategic improvement of quality of medical services in order to minimize socio-economic losses from environmental violations may not be considered effective for any subject of the Russian Federation. In the process of statistical analysis of the results of applying the model significant inter-regional differences of per capita levels of social and economic damage from environmental violations were revealed and effective conservation strategies for each of the studied region were identified.

In the studies of Anopchenko T. (2008) the model of "socio-economic damage and environmental damage" is also proposed for strategic management of ecological-economic risks, but the description of these dependencies uses not linear, as in the previous work, but the power function:

$$
\left\{\begin{array}{l}
M=a_{0} \cdot D^{a_{1}} \cdot P^{a_{2}} \cdot V^{a_{3}} \cdot W^{a_{4}}, \\
D=b_{0}+b_{1} I+b_{2} L, \\
I=c_{0}+c_{1} M
\end{array}\right.
$$

where $M$ is the morbidity of the population; $V$ and $W$ are indicators of pollutants; 
$D$ - provision of population with health services; $I$ - level of per capita income; $P$ is the satisfaction of housing needs.

This model assumes a direct dependence of the volume of harm to human health on exposure to pollutants, the magnitude of average income, availability of health services and quality housing, and income - on the health of the population, that is conditioned by the loss of working time and the reduction of wages in the case of high morbidity.

\section{DISCUSSION}

Materials discussed during research roundtables in the Southern Federal University, in which identified and taken into account the following observations.

Both considered models use the criterion of population morbidity for characteristics of the socio-economic damage from pollution of the environment. In our view, the proposals of both authors have some drawbacks. So, from the equation of the overall environmental hazard follows that in some cases the growth of emissions and discharges dynamics contributes to the growth in the number of polluters per capita. In addition, the characteristics of the level of ecological danger itself, expressed not only in terms of number of enterprises of pollutants or security health service, is weakly unbiased.

Thus, in the considered models, the risk factor is not fully taken into account; this fact may lead to wrong conclusions. So, the lack of attention to risk factors in the works of Ryumina E. (Abrahamian at al., 2002) promotes the formation of not informed statements about improving the environmental sustainability of territories in the conditions of reducing the quality of the technosphere at expense of the improvement of the ecosystem, however, the growing anthropogenic pressure on the ecosystem already is a risk-causing factor. Therefore, an important condition for the objectivity of social-ecological models is the use of indicators of economic and ecological risks, and in view of the susceptibility of the system objects not to single risks, but to their combined influence, it is necessary to compare objects of risk by all indicators, which necessitates the use of integrated risk criteria.

Problems of integral indicators modeling were addressed by Aivazian S. (2002), who investigated the quality of life of the population depending on training opportunities and forms of their presentation in the source statistics.

In our opinion, the construction of integral indicator of socio-environmental risk should be made using models of ordered multiple choice, because the use of the linear structure of the integral indicators, including those obtained by the method of principal components, allows obtaining the same estimates for inhomogeneous objects. In addition, the complete solution of the partial non-compensability is only possible when using a non-linear structure of such models.

The use of models of multiple choice for building integrated indicators involves the preliminary classification of the studied objects by the level of quality of the analyzed integral properties. The task of identifying homogeneous groups of objects can be treated by classical methods, among which are hierarchical and iterative cluster analysis, and by advanced neural network classification methods (Voischeva at al., 2007). Another approach to objects' typing by integral properties is data compression methods, involving the reduction of dimensionality of feature space, these include component-factor analysis and multidimensional scaling. These methods have both advantages and disadvantages.

The method of multidimensional scaling, in our opinion, is the most objective for the task. Multidimensional scaling can be based on three approaches: linear, nonlinear and non-metric (monotone) (Terekhina, 1986). The linear approach made by Torgerson W. S. is orthogonal spatial design in specific areas, characterized by a certain range of values. The non-linear approach involves the transformation of the original space with minimal distortion of the original differences on the basis of quality criteria called "stress", which measure the degree of divergence of the baseline differences and the resulting distances. The apparatus of nonlinear optimization is directed to define the configuration space, which allows to minimize the "stress".

Non-metric approach takes into account the differences in the original matrix and matrix of metric space distances and involves not the approximation of these differences but the selection of values sequence, characterized by 
monotony in relation to the original data and a maximum accordance with the exact distances.

Consequently, non-linear and non-metric approach is not limited by an orthogonal design, which is to their advantage, and allows to get the best display of values in the space of a smaller dimension, compared to the linear approach, due to the possibility of a large increase and decrease smaller distance.

All approaches of multidimensional scaling are based on remote model, involving the approximation of differences in the stimuli using the distances between the corresponding points. Typically, these distances are determined by the Euclidean metric, with insensitivity to the axis rotation and the origin transfer (Terekhina, 1983). Currently, however, the development of computer technology allows using more efficient algorithms of non-metric scaling for the statistical packages.

Methods of hierarchical cluster analysis and multidimensional scaling are similar in usage of the vicinity characteristics for obtaining the ideas about the structure of objects. While the cluster approach assumes the objects' quality group for representation of their structure, and the multidimensional scaling approach - quantitative coordinate representations of objects (Terekhina, 1983), which, for example, for a two-level scale are represented as points on the plane. Visibility and ease of these methods of presenting the results of object classification by risk level allow more informed management decisions.

Cluster analysis supposes a single method of objects' grouping in which all objects of one group should be different from all other objects. A multidimensional scaling approach is less demanding to basic information and allows you to combine objects into groups on the basis of the approximate degree of their similarity with other objects. However, the use of iterative methods of cluster analysis, including the widespread k-means method, can lead to inaccurate results in comparing features a.o. the use of the Euclidean metric in the case of high correlation of analyzed characteristics, avoidance of which while noting large number of signs is almost impossible. It is possible to overcome this problem while using the metrics of Mahalanobis type and modifications of the original algorithm (Anopchenko and Pashkova, 2008), but, unfortunately, today statistical packages allowing the implementation of these tasks are absent.

Unlike multidimensional scaling, which is essentially closer to factor than to the cluster analysis, non-metric scaling does not require subordination of the investigated data multivariate normal distribution and a linear relationship that allows using a smaller number of factors (axes) and allows easier interpretation of the results.

Multiple selection models’ assessment can be made by the method of maximum probability which involves the description of the distribution of models' errors on the basis of the law of distribution (normal, logistic, etc.). Compliance with this condition in most cases is not challenged, and the choice of modeling method is based on a posteriori comparisons. However, in case of a breach of these viability terms obtained by the method of maximum probability estimates is questionable. In addition, in some cases, the distribution of the model's errors generally cannot be described by the known laws of distribution and requires the use of other methods of approximation.

\section{CONCLUSIONS}

Multiple choice models also assist to identify the factors of socio- ecological risks. However, the data of model, having undoubted practical utility in the development of scenarios of socio-economic development of the city in terms of forecasting characteristic risks, not able to fully reflect the mutual influence of socio-economic factors of development and level of economic and ecological risks. So, in the case of using the characterization of the level of socio-ecological risks of quantitative indicators of damage, such as that proposed by Anopchenko (2008), the consideration of the identified interconnections can be calculated using a system of simultaneous regression equations. However, you should note that this approach is impossible in the case of nonquantifiable indicators integrated risk.

For the evaluation of integrated risk quality indicators it seems to be expedient to transit from ordinal scale of risk to nominal one, that although tolerate a certain loss of information, but allows the use of a multi-dimensional binary choice model. 
Thus, in accordance with its purpose, we presented the characteristics of socio- ecological risk as a subject of study, research and the necessity for socio-ecological models of integrated risk indicators, reflecting the quality, condition and levels of environmental sustainability in urban areas were scientifically substantiated. Analyzing the works of domestic and foreign researchers we have studied the ways of the convolution of particular indicators, based on the principles of thermodynamics and the laws of conservation of matter and energy, we have considered the possibility of accounting for the multiplicity of factors influencing the probability of risk. The scientific result of the study is the proposal of a simulation of the integral index of socio-ecological risk-based models of multiple choices.

\section{ACKNOWLEDGEMENTS}

We are grateful for the support of the Administration of the Southern Federal University and to the scientific community of management faculty of this university.

\section{REFERENCES}

1. Abrahamian, S.I., Luchsheva, V.V., Ryumina, E.V., Ecological-economic efficiency of investment projects. Environmental Economics, 2002; 2: 17-25.

2. Aivazyan, S., Econometric modeling: a comparative analysis of the integral characteristics of the quality of life of the population of subjects of the Russian Federation. Moscow: MESI, 2002.

3. Anopchenko, T.Y., Environmental-economic risks in urbanized areas: the concept, causes, consequences (Doctoral dissertation). Rostov State Building University, Rostov-on-Don, Russia, 2008.

4. Anopchenko, T.Y., Pashkova, A.Y., Development of econometric models to assess the regional economic damage to the health of the population. Regional economy: theory and practice, 2008; 10: 116-120.

5. Assessment of environmental management systems., Proceedings of the International Workshop on Indicators of compliance and enforcement of environmental law. International Network for Environmental Compliance and Enforcement Organization for Economic Cooperation and Development (OECD), Paris,
France, 2003.

6. Bakumenko, L., Korotkov, P., Integrated assessment of the quality and extent of the environmental sustainability of the region. Journal of applied econometrics, 2008; 1: 7392.

7. Brocki, W.A., A polluted golden age. Economics of Natural \& Environmental Resources (Routledge Revivals), 2013; 441.

8. Burkov, V.N., Novikov, D.A., Schepkin, A.V. Models and mechanisms of management of ecological and economic systems. Control science, 2009; 1: 2-7.

9. Chetyrkin, E.M., Financial mathematics. Moscow: Delo, 2000.

10. Dediu, I.I., Ecological Encyclopedic Dictionary, 1989.

11. Dewulf, J., Van Langenhove, H. (Eds.)., Renewables-based technology: sustainability assessment. John Wiley \& Sons, 2006.

12. Dubrov, A.M., Baranovskaya, T.P., Khrustalev, E.Y., Lagosha, B.A., Modeling of risk situations in the economy and business. Moscow: Finance and statistics, 2001.

13. Dvoretsky, L.M., The Ecological component of the economic evaluation of real estate (Doctoral dissertation). Russian Academy of Sciences, Moscow, Russia, 2006.

14. Eklasheva, O.V., Modeling of ecological factor in the economic dynamics of a city. Moscow, MAKS Press, 2005.

15. Esty, D. C., Levy, M., Srebotnjak, T., \& De Sherbinin, A., Environmental sustainability index: benchmarking national environmental stewardship. New Haven: Yale Center for Environmental Law \& Policy, 2005; 47-60.

16. Forrester, J.W., World dynamics (Vol. 59). Cambridge, MA: Wright-Allen Press, 1971.

17. Grinin, A.S., Orekhov, N.A., Novikov, V.N. Mathematical modeling in ecology. Moscow: UNITY-DANA, 2003.

18. Gurman, V.N., Ryumina, E.V. (Eds.)., Modeling of socio-ecological-economic system of a region. Moscow: Nauka, 2003.

19. Kashenkova, O.V., Ecological component in the assessment of socio-economic development. Environmental Economics, 2009; 1: 14-24.

20. Khokhlov, N.V., Risk management. Moscow: UNITY-DANA, 2001.

21. Kolesnikov, S.I., Ecological bases of nature management. Rostov-on-Don: Mart, 2005.

22. Krass, M.S., Chuprunov, B.P., Mathematics in economics. Mathematical methods and models. Moscow: Finance and Statistics, 2007.

23. Leontiev, V.V., Inter-Sectoral economy. Moscow, Economics, 1997. 
24. Lopatnikov, L.I., Economical and mathematical dictionary: dictionary of modern Economics. Moscow: Delo, 2003.

25. Mashintsov, E.A., Assessment of environmental impact of environmental factors on the health status of the population anthropogenically loaded areas on the basis of the system approach (Doctoral dissertation). Tula State University, Tula, Russia, 2007.

26. Meadows, D., Randers, J., \& Meadows, D. Limits to growth: the 30-year update. Chelsea Green Publishing, 2004.

27. Murzin, A.D., Principles of decision making modeling on the management of socio-ecological and economic risks of development of urban areas. Engineering journal of Don, 2012; 3: 626629.

28. Russian Federation. Laws., Federal law "On environmental protection”. Moscow: Rior, 2006.

29. Russian Federation. Laws., Federal law "On technical regulation”. Moscow: Rior, 2002.

30. Onishchenko, G.G., Novikov, S.M., Rachmaninoff, Y.A., Avaliani, S.L., Bushtueva, K.A., Basis of risk assessment for public health caused by chemical pollutants in the environment. Moscow: Research Institute of ECH and the CRP, 2002; 408.

31. Pashkova, A.Y., Assessment of damage from environmental pollution in the system for ecologically safe development of the Russian economy (Doctoral dissertation). Southern Federal University, Rostov-on-Don, Russia, 2008.

32. Peccei, A., The human quality. Elsevier, 2013.

33. Reimers, N.F., Nature Management: Dictionary Directory. Moscow: Mysl, 1990.

34. Gracheva, M.V., Sekerin, A.B., Risk-management of the investment project. Moscow: UNITY, 2008.

35. Ryumina, E.V., Analysis of ecological-economic interactions. Moscow: Nauka, 2000.

36. Ryumina, E.V., Environmental costs of the economy. Moscow: PH “IBA”, 2011.

37. Ryumina, E.V., Estimation of economic damage from environmental violations in developing plans and programs. Impact assessment on the environment in the States-participants CIS and Eastern Europe. Moscow: National center of environmental program, 2004; 33-40.

38. Saied, K., The Design of change for economic development: A behavioral modeling and simulation approach. Bangkok, Thailand: Asian Institute of Technology, 1988; 297.

39. Sholomitsky, A.G., Risk Theory: choice under uncertainty and risk modeling. Moscow: $\mathrm{PH}$ HSE, 2005; 400.

40. Terekhina, A.Y., Multidimensional scaling in psychology. Psychological journal, 1983; 1(4): 76-88.

41. Terekhina, A.Y., Analysis of data by methods of multidimensional scaling. Moscow: Nauka, 1986; 168.

42. Tikhomirov, N.P., Potravny, I.M., Tikhomirova, T.M., Methods of analysis and management of ecological-economic risks. Moscow: UNITYDANA, 2003; 350.

43. Tsyganov, M.A., Statistical analysis and forecasting of anthropogenic pollution in the system of ecological security of the Republic of Mordovia. Vestnik of Samara State University of Economics, 2007; 9: 137-142.

44. Vagapova, Y.Y., Modeling of economic growth taking into account environmental and social factors. Moscow: MAKS Press, 2007; 126.

45. Voischeva, O.S., Davnis, V.V., Tinyakova V.I., Econometric modelling of ratings in business. Voronezh Central Black Earth Book Publishers, 2007.

46. Wackernagel, M.A., Rees, W.E., Our ecological footprint: reducing human impact on the earth (No. 9). New Society Publishers, 1998.

47. World Bank Group (Ed.)., World development indicators 2012. World Bank Publications, 2012. 